\title{
Cilia in hereditary cerebral anomalies
}

Sophie Thomas ${ }^{1,}{ }^{*}$, Lucile Boutaud ${ }^{1}$, Madeline Louise Reilly ${ }^{2,3}$, and Alexandre Benmerah ${ }^{2, *}$

${ }^{1}$ Laboratory of Embryology and Genetics of Human Malformation, INSERM UMR 1163, Paris Descartes University, Imagine Institute, 75015 Paris, France.

${ }^{2}$ Laboratory of Hereditary Kidney Diseases, INSERM UMR 1163, Paris Descartes University, Imagine Institute, 75015 Paris, France.

${ }^{3}$ Paris Diderot University, 75013 Paris, France.

* To whom correspondence should be addressed:

Alexandre Benmerah, Institut Imagine, 24 boulevard du Montparnasse, 75015 PARIS, France.

Tel: +33 1427543 44, fax: +33 1427542 25, email: alexandre.benmerah@inserm.fr

Sophie Thomas, Institut Imagine, 24 boulevard du Montparnasse, 75015 PARIS, France.

Tel : +33 +331427543 10, fax: +33 1427542 25, email: sophie.thomas@inserm.fr 
Abstract:

Ciliopathies are complex genetic multisystem disorders causally related to abnormal assembly or function of motile or non-motile cilia. While most human cells possess a non-motile sensory/primary cilium (PC) during development and/or in adult tissues, motile cilia are restricted to specialized cells. As a result, PC-associated ciliopathies are characterized by high phenotypic variability with extensive clinical and genetic overlaps. In the present review, we have focused on cerebral developmental anomalies which are commonly found in PC-associated ciliopathies and which have mostly been linked to Hedgehog signaling defects. In addition, we have reviewed emerging evidence that PC dysfunctions could be directly or indirectly involved in the mechanisms underlying malformations of cerebral cortical development including primary microcephaly. 


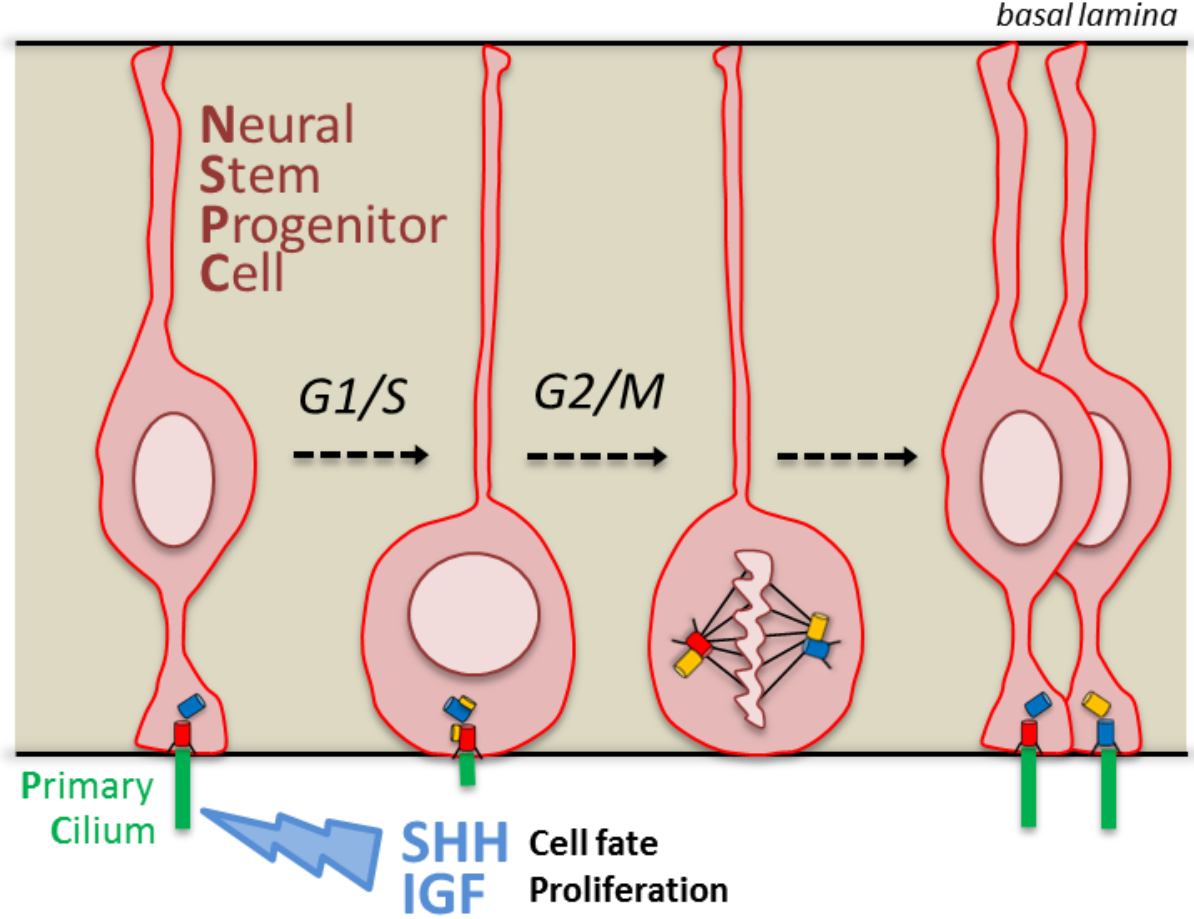

Ciliopathies are complex genetic disorders linked to primary cilia dysfunction. Cerebral anomalies are one of the manifestations observed in ciliopathies which have mainly been linked to defective Hedgehog signaling. Additionally, in neuron progenitors, ciliary disassembly controls the duration of the $\mathrm{G} 1 / \mathrm{S}$ transition and, therefore, proliferative versus neurogenic divisions. Increased cilium length or defects in disassembly may also contribute to microcephaly by a loss of progenitors. 


\section{Abbreviations}

ACLS: acrocallosal syndrome

BB: basal body

BBS: Bardet Biedl Syndrome

CC: corpus callosum

CSF: cerebrospinal fluid

HLS: hydrolethalus syndrome

IFT: intraflagellar transport

JBTS: Joubert Syndrome

KIF: Kinesin family member

MCD: malformations of cerebral cortical development

MKS: Meckel-Grüber Syndrome

MPD: microcephalic primordial dwarfism

NTD: Neural Tube Defect

NSPC: neural stem and progenitor cells

OFD: orofaciodigital syndrome

PC: primary cilia

PCD: Primary ciliary dyskinesia

PCP: Planar Cell Polarity

SHH: Sonic Hedgehog 


\section{Introduction}

Cilia are highly conserved organelles which can be motile or immotile (Satir and Christensen, 2007). All cilia are assembled from a basal body, which corresponds to the mother centriole of the centrosome for immotile sensory or primary cilia (PC), and to amplified centrioles for motile cilia in multiciliated cells. Ciliogenesis is a complex process involving the docking of centrioles to intracellular membranes (primary ciliary vesicles), through centriolar distal appendages (Figure 1A), and the subsequent elongation of the microtubule-based axoneme thanks to a highly conserved transport machinery, the intraflagellar transport (IFT), which mediates import and export of ciliary components inside and from the ciliary compartment (Figure 1B). Indeed, both the 'cilioplasm' and ciliary membrane are separated, respectively, from the cytoplasm and plasma membrane through the 'ciliary gate' based on two important structures, the transition fibers (centriolar distal appendages) and the transition zone. Ciliary components are efficiently transported through this barrier by the IFT machinery, IFT-A and IFT-B subcomplexes, associated with anterograde (Kinesin II, KIF3A/B) and retrograde (cytoplasmic dynein 2) motors, allowing the dynamic transport of ciliary receptors and signaling intermediates in and out of the PC (Figure 1B; (Lechtreck, 2015)). While motile cilia are formed only on terminally differentiated cells (Spassky and Meunier, 2017), PC are additionally also found on cells able to divide, including stem cells. In proliferating cells, PC are disassembled through a complex, cell cycle-linked process (Sánchez and Dynlacht, 2016) allowing the release of the duplicating centrosome from the plasma membrane to enable its function in mitotic spindle assembly. Interestingly, at least in some cell types (see below), a ciliary membrane remnant remains associated with the mother centriole during this process (Figure 1A). This ciliary-primed older mother centriole will be asymmetrically inherited by one of the daughter cells, which will then ciliate and respond to PC-dependent signals more rapidly (Anderson and Stearns, 2009; Paridaen et al., 2013).

Motile cilia line the epithelial surfaces of the respiratory tract, testis efferent ducts, oviduct and brain ventricles, where they are required for the oriented movement of fluids or gametes (Spassky and Meunier, 2017). The characteristic disease of motile cilia is primary ciliary dyskinesia (PCD), a group of genetic diseases characterized by chronic airway infections, sinusitis and otitis media. Some patients can also present with situs inversus and congenital heart disease in the case of Kartagener syndrome (Mitchison and Valente, 2017; Reiter and Leroux, 2017). In the brain, defects in motile cilia can be associated with hydrocephalus characterized by the enlargement of brain ventricles resulting from an accumulation of cerebrospinal fluid (CSF) in the cerebral ventricles (Lee, 2013; Spassky and Meunier, 2017).

Primary cilia (PC) are sensory/signaling cilia present on most cell types during development where they control key signaling pathways. The most well characterized cilia-dependent signaling 
pathway in vertebrates is Sonic Hedgehog (SHH), which plays a key role in vertebrate organogenesis (limbs, brain) controlling proliferation and specification. Most of the components of this pathway including Patched (SHH receptor, Ptch), Smoothened (Smo) and GLI transcription factors, were shown to dynamically localize to PC depending on SHH stimulation. Furthermore, SHH signaling culminates in the processing of the bifunctional GLI transcription factors to generate GLI activator or repressor forms in a cilium-dependent manner. Pathway activation results in the removal of Ptch from the ciliary membrane, while Smo accumulates preventing Gli processing (mainly GLI3R) and leading to the generation of GLI activator forms (mainly GLI2A; (Bangs and Anderson, 2017)). In addition to $\mathrm{SHH}, \mathrm{PC}$ were also involved in other important signaling pathways during development (PDGF $\alpha$, TGF $\beta$ ) and tissue homeostasis/function, including sensing of molecules (photoreceptors outer segment (photons)) or of mechanical clues (Kidney epithelia, chondrocytes; (Nishimura et al., 2019)). In the brain, PC play crucial roles during cerebral development, especially in early patterning of the neural tube, neural stem cell pool regulation, neural differentiation and migration (GuemezGamboa et al., 2014; Youn and Han, 2018).

Impaired assembly or function of PC lead to a still growing group of highly heterogeneous inherited diseases collectively called (primary) ciliopathies which can affect almost all tissues/organs (Mitchison and Valente, 2017; Reiter and Leroux, 2017). The notion of a "ciliopathic" disorder was first attributed to Bardet-Biedl syndrome (MIM \#209900, BBS; (Ansley et al., 2003)), a condition characterized by retinal dystrophy, cystic kidneys, polydactyly, obesity and intellectual disabilities. Each of these classical ciliopathy-associated manifestations and others (hepatic fibrosis, skeletal dysplasia, etc...) can be found isolated or in specific associations in affected individuals, then defining syndromic forms. PC-associated ciliopathies are mostly recessively inherited and genetically highly heterogeneous, with both major phenotypic and genetic overlap. Indeed, allelism (a common causal gene for distinct disorders), has been shown between several ciliopathies, such as between Joubert (MIM \#213300, JBTS) and Meckel (MIM \#249000, MKS) syndromes where almost 13 common genes have so far been reported, supporting the notion that MKS represents the extreme lethal form of JBTS.

Developmental brain anomalies are among the characteristic and frequent ciliopathyassociated manifestations (Guemez-Gamboa et al., 2014). Besides hydrocephalus, which could be linked to both motile and PC dysfunctions, cerebellar hypoplasia and corpus callosum malformations, together with neural tube closure defects, are manifestations classically associated with abnormal PC biogenesis or function. Microcephaly with or without malformations of cerebral cortical development $(\mathrm{MCD})$ can also occasionally be attributed to PC-ciliopathies but are not commonly categorized among classical ciliopathy-associated manifestations. Recent data, however, indicate 
that PC dysfunctions could participate, directly or indirectly, in the pathological mechanisms underlying microcephaly and/or MCD.

Here, we have summarized the known mechanisms involved in ciliopathy-associated brain anomalies in humans and emphasized the emerging evidence implicating PC dysfunctions in cerebral cortical disorders, particularly in primary microcephaly.

\section{Ciliopathy-associated cerebral anomalies:}

The key role of cilia during brain development in vertebrates was first demonstrated in a genetic mouse screen for mutations affecting dorso-ventral patterning of the neural tube, which showed that disruption of genes coding for IFT subunits or for the IFT anterograde motor protein Kif3a are required for SHH signaling (Huangfu et al., 2003). This initial connection between SHH signaling and PC function in mammals, together with the delineation of the brain defects observed in various ciliopathies, largely contributed to the explosion of interest in PC. Here we have focused on the major ciliopathy-related, developmental brain disorders present in ciliopathy cases in humans and which have been largely linked to misregulation of the SHH pathway.

\section{Neural tube defects:}

Neural tube defects (NTDs) include a large variety of central nervous system malformations which may be classified in 1) open forms (e.g. anencephaly/exencephaly, spina bifida aperta) resulting from defects of primary neurulation, 2) closed forms (e.g. spina bifida occulta) resulting from defects of secondary neurulation and 3 ) herniation forms (e.g. encephalocele) due to post-neurulation defects (Greene and Copp, 2014). Anencephaly, as well as occipital encephalocele, can manifest in PCciliopathies, including MKS and Hydrolethalus syndrome (HLS, MIM \#614120; see Corpus callosum agenesis).

In various vertebrate species, NTD have been closely linked to abnormal SHH signaling (Greene and Copp, 2014; Shimada and Mukhopadhyay, 2017), which orchestrates neural tube patterning (Ribes and Briscoe, 2009; Bangs and Anderson, 2017). SHH is initially secreted by the notochord and then by cells of the floor plate (Figure 2B). The subsequent ventral to dorsal gradient of SHH leads to the differentiation of neuron subtypes by the induction of specific sets of transcription factors. In addition, SHH also appears to act as a negative regulator of the dorsolateral bending of the neural tube which happens at mid spinal levels (where SHH is low; Figure 2B, red arrows) through coordinated apical domain contraction of neuroepithelial cells and is required for the closure of the neural tube (Nikolopoulou et al., 2017). Accordingly, overactivation of the pathway is commonly associated with closure defects, as observed in Ptch1-/- (Goodrich et al., 1997) or Sufu - 
/- mice (Cooper et al., 2005), which show an expansion of ventral markers and loss of dorsal markers and exhibit exencephaly. On the contrary, complete absence of SHH signaling in SHH deficient mice (Chiang et al., 1996) or reduced SHH signaling in Smo -/- mice (Zhang et al., 2001) leads to severe dorso-ventral patterning defects of the neural tube which is closed but lack forebrain separation leading to holoprosencephaly (HPE; MIM \#236100), a spectrum of midline defects in which cyclopia is the most severe form (Dubourg et al., 2018). Mouse models of the invalidation of PC-genes often present with NTD but the situation appears more complicated than a simple link between PC presence/absence or excess/reduced SHH activity and NTD versus HPE. In the ventral spinal cord, some IFT-A mutants with almost normal PC present a phenotype reminiscent of SHH overactivation including an expansion of ventral cell types at the expense of dorsal cell types and NTD. On the other hand, additional IFT-A mutants with abnormal PC (very short and bulged PC) show dorso-ventral patterning defects consistent with reduced SHH activity (loss of ventral cell fates) similar to those observed in IFT-B mutants which lack cilia but both can still present exencephaly (for review see Bangs and Anderson, 2017).

In conclusion, besides the apparently simple dichotomy between mutants with an invalidation of genes encoding direct components of $\mathrm{SHH}$ signaling leading either to overactivation or reduced activity of the pathway with subsequent NTD or not, ciliary mutants represent a complex group with varying consequences on neural tube closure. Importantly, emerging, and sometimes controversial, roles of PC in other signaling pathways have suggested that their disruption could also be involved in NTD. Among them, the planar cell polarity (PCP) pathway is largely associated with NTD, although the types of NTDs are distinct from those observed in ciliary mutants. Indeed, PCP mutants exhibit severe forms of NTD involving the entire neural tube (craniorachischisis) whereas NTD in cilia mutants are mostly restricted to the cranial region (exencephaly; (Nikolopoulou et al., 2017)). Thus, in view of all those evidence in animal models, PC are clearly playing a key role in neural tube patterning and closure through regulation of SHH signaling, but further investigations are needed to improve our understanding on the involvement of PC in the process of neural tube closure, in particular to delineate the potential involvement of other PC-dependent signaling pathways.

\section{Corpus callosum agenesis:}

The corpus callosum (CC) is the largest axonal tract or commissure in the brain, consisting of over 190 million axons from callosal neurons connecting homologous cortical areas of the two cerebral hemispheres (Figure $3 \mathrm{~A}, \mathrm{~B}$ ). The $\mathrm{CC}$ influences higher cognition, social interaction and language (Edwards et al., 2014). CC development is a highly complex process with several steps from early telencephalic patterning, callosal neuron expansion and specification, to the guidance of callosal 
axons to cross the midline and reach specific contralateral regions. CC malformations represent the most frequent brain malformations observed at birth in humans and are highly heterogeneous, ranging from complete to partial agenesis or hypoplasia (Figure $3 C, D, F)$. CC malformations can be isolated but are frequently part of congenital syndromes; including several ciliopathies. In particular, acrocallosal syndrome (ACLS, MIM \#200990) is characterized by the association of CC agenesis or hypoplasia with intellectual deficiency, polydactyly and craniofacial features. We have previously identified KIF7 mutations as responsible for this condition, as well as for an overlapping lethal ciliopathy, the hydrolethalus syndrome (HLS, MIM \#614120; (Putoux et al., 2011)).

KIF7 is a ciliary kinesin which plays a crucial and conserved role in the organization of a SHH signaling platform at the distal end of PC (Bangs and Anderson, 2017; Reilly and Benmerah, 2019). In both humans and mice, KIF7 depletion leads to overactivation of the SHH pathway associated to abnormal GLI3 processing (Liem et al., 2009; Putoux et al., 2011). Interestingly, GLI3 mutations in humans lead to Greig syndrome (MIM \#175700), an ACLS overlapping syndrome with frequent CC agenesis (Vortkamp et al., 1991; Biesecker, 2008). Other ciliopathies are associated to CC malformations including the Orofaciodigital syndrome I (OFD1, MIM \#311200; (Thauvin-Robinet et al., 2013)) as well as in Orofaciodigital syndrome IV (OFD4, OMIM \#258860) associated to mutations in TCTN3 (Thomas et al., 2012). OFD1 is playing a key role in centriole elongation and therefore in ciliogenesis (Ferrante et al., 2006; Singla et al., 2010), whereas TCTN3 is a key component of the transition zone which is implicated in SHH signaling (Garcia-Gonzalo et al., 2011; Wang et al., 2017). The growing number of ciliary genes identified as responsible for ciliopathies associating CC malformations, along with the use of murine models of ciliary gene depletion (Benadiba et al., 2012; Laclef et al., 2015; Putoux et al., 2018), has revealed the role of cilia-dependent SHH signaling, especially through regulation of GLI3 processing, in CC development. Indeed, GLI3 was previously shown to play key roles during brain development and neural tube patterning (Theil et al., 1999; Persson et al., 2002) and the introduction of one or two alleles of Gli3 ${ }^{\Delta 699}$, which produces only the short isoform of Gli3 (repressive form; GLI3R) rescues several brain defects observed in ciliopathy models, including CC anomalies (Besse et al., 2011; Laclef et al., 2015). For instance, in Kif7-/- mice, which recapitulate major ACLS features, including CC agenesis, the introduction of the Gli3 ${ }^{\Delta 699}$ allele is sufficient to rescue CC anomalies as well as specific patterning defects of the cortical septum boundary responsible for the altered distribution of guidepost cells required to guide callosal axons through the midline (Putoux et al., 2018).

Interestingly, CC malformations can also be found in association with malformations of cerebral cortical development (MCD) and primary microcephaly, notably in the case of mutations in WDR62 (Bilgüvar et al., 2010), ASPM (Passemard et al., 2009), RTTN (Kheradmand Kia et al., 2012; Chartier et al., 2018) or NDE1 (Alkuraya et al., 2011; Bakircioglu et al., 2011) all encoding proteins 
more or less associated to PC dynamics and/or functions. In those cases, PC dysfunctions might affect callosal neuron generation, in addition to callosal axon guidance (see in 'malformations of cerebral cortical development').

\section{Cerebellar hypoplasia:}

Cerebellum function was historically restricted to sensory-motor processing but it has also long been associated to cognition. JBTS is the archetypal ciliopathy affecting cerebellar development. It was first described in 1969 (Joubert et al., 1969, 1999) and is characterized by a cerebellar and brainstem malformation which results in the appearance of a molar tooth on axial brain magnetic resonance imaging and was thus called "the molar tooth sign" (Figure 3A, E, G). This anomaly arises from the combination of cerebellar vermis hypodysplasia, thick, elongated and horizontally oriented superior cerebellar peduncles and a deep interpeduncular fossa (Maria et al., 1997; Valente et al., 2013). SHH signaling (Wechsler-Reya and Scott, 1999) and PC (Chizhikov et al., 2007; Spassky et al., 2008) have been shown to play a key role during mouse cerebellar development by promoting the expansion of cerebellar granule cell precursors, suggesting that disruption of this pathway underlies the cerebellar malformations observed in ciliopathy cases. A defect in the SHH-dependent expansion of granule cell precursors was further demonstrated in human in both the cerebellar hemispheres and vermis in MKS and JBTS fetuses (Aguilar et al., 2012), likely explaining the global cerebellar phenotype. The specific vermis dysplasia may be linked to another earlier mechanism potentially involving defective WNT signaling, another crucial pathway for cerebellar development (Hatten and Roussel, 2011), which was also linked to PC (Lancaster et al., 2011). Of the mutations thus far identified in JBTS, most of the affected genes encode ciliary proteins which localize to the transition zone and play a key role in SHH signaling (Bangs and Anderson, 2017; Mitchison and Valente, 2017), while their contribution to WNT signaling in this context remains to be fully explored.

\section{Hydrocephalus:}

Hydrocephalus is characterized by an enlargement of the brain ventricles resulting from an excess of cerebrospinal fluid (CSF) secondary to impaired CSF flow, blockage of aqueducts connecting the brain ventricles, excess CSF production or a lack of CSF reabsorption. CSF is produced by the choroid plexus of the lateral, third and fourth ventricles and normally flows from the lateral ventricles to the third ventricle, through the aqueduct of Sylvius, into the fourth ventricle, and finally along the spinal channel and subarachnoid space, where the CSF is reabsorbed into the blood or lymphatic system (Lee, 2013). The coordinated and oriented beating of motile cilia at the apical surface of ependymal cells participates in establishing CSF flow (Spassky and Meunier, 2017). Defects in either the 
specification of ependymal cells, the amplification/orientation of basal bodies or ciliary beating are associated to impaired CSF flow and subsequent hydrocephalus. Surprisingly, while hydrocephalus is frequently observed in many animal models of PCD, although with mouse strain variability, it is only occasionally present in individuals diagnosed with PCD (Mitchison and Valente, 2017). This difference suggests that other genetic mechanisms underlie distinct susceptibility to hydrocephalus (Lee, 2013; Spassky and Meunier, 2017).

Hydrocephalus is also one of the manifestations of severe PC ciliopathies including MKS, OFD and HLS. Most of the causal genes identified for those ciliopathies encode PC-associated proteins crucial for SHH signaling (see previous chapters), while HYLS1, the first gene identified in HLS, was involved in various steps of ciliogenesis including the assembly of transition fibers, the docking of basal bodies onto membranes (motile cilia) and transition zone organization (Dammermann et al., 2009; Wei et al., 2016). Whether the proteins implicated so far have potential functions either at motile cilia functions and/or the specification/differentiation of ependymal cells through their known function in the SHH pathway (Yu et al., 2013) remain to be investigated. Interestingly, it was shown that hydrocephalus in Ift88 mutant mice develops before the appearance of motile cilia and has been attributed to the overproduction of CSF by the choroid plexus resulting from defects in PC (Banizs et al., 2005) which then could also explain the hydrocephalus present in severe PC ciliopathies.

\section{Could microcephaly be regarded as a ciliopathy-associated phenotype?}

The cerebral cortex is a highly organized, six-layered structure that contains billions of neurons and glial cells. This region of the brain is responsible for higher-order cognition and reasoning, language, advanced motor skills, and social-emotional behavior and has undergone pronounced expansion during evolution from the small and smooth (lissencephalic) cortex of mice, to the large and profoundly folded (gyrencephalic) cortex of humans. In the last decade, substantial progress has been made in identifying the cellular and molecular events regulating cortical expansion and folding. In particular, multiple neural stem and progenitor cells (NSPC) have been identified and classified based on specific hallmarks including the mode of cell division, proliferative capacity, polarity and location of mitosis ((Hansen et al., 2010; Lui et al., 2011; Nonaka-Kinoshita et al., 2013); Figure 4A). Primary microcephaly (MIM \#251200) is characterized by a reduced brain size present at birth (or antenatal) and which can occur either isolated or in association with malformations of cortical development (MCD), including gyration defects. Primary microcephaly is highly genetically heterogeneous with several genes encoding proteins involved in the biology of the centrosome and/or microtubules dynamics (Naveed et al., 2018; Romero et al., 2018). While these proteins were shown to play essential roles in NSPC cell cycle dynamics and checkpoints through their roles in cytoplasmic microtubules and mitotic spindle organization/dynamics (Faheem et al., 2015; Morris- 
Rosendahl and Kaindl, 2015; Doobin et al., 2017), recent evidence also stressed their involvement in PC dynamics and/or signaling properties.

The first evidence for a possible link between PC and microcephaly came from the identification of mutations in PCNT in patients with microcephalic osteodysplastic primordial dwarfism, type II (MOPDII, MIM \#210720; (Rauch et al., 2008)) belonging to the group of microcephalic primordial dwarfism (MPD) associating microcephaly and dwarfism (Bober and Jackson, 2017). Pericentrin, first described as an integral component of the pericentriolar matrix of the centrosome, involved in cytoplasmic microtubules dynamics and mitotic spindle organization/orientation (Delaval and Doxsey, 2010), is also required for ciliogenesis (Jurczyk et al., 2004; Martinez-Campos et al., 2004; Galati et al., 2018). Subsequently, mutations in other MPD causal genes linked to PC biogenesis were identified, including in PLK4 in patients with characteristic ciliopathy phenotypes (Martin et al., 2014). However, mutations in both genes primarily affect centrosome/centriolar functions (PCNT) and number (PLK4), which could be the direct cause of the observed phenotypes, as in the cases of mutations in other genes encoding centrosome-associated proteins (Faheem et al., 2015; Romero et al., 2018).

Another similar and unexpected association of MPD and PC was evidenced in the context of the Meier-Gorlin syndrome (MGS, MIM \#224690) for which mutations were identified in genes encoding subunits of the origin recognition complex (ORC), a key component of the DNA replication licensing machinery (Klingseisen and Jackson, 2011). Unexpectedly, the ORC subunit ORC1 was also shown to control centriole duplication through negative regulation of Cyclin E-CDK2 (Hossain and Stillman, 2012) and ORC mutations in affected individuals result in ciliogenesis defects as well as cell cycle progression delay, which likely contributes to both bone development defects and microcephaly (Stiff et al., 2013). The role of ORC in ciliogenesis in vivo was further recently confirmed in zebrafish where knockdown of the expression of ORC subunits resulted in classical ciliopathyassociated phenotypes, in addition to microcephaly (Maerz et al., 2019). However, and again, the relative contributions of centrosome, cell cycle (S phase progression) and PC defects to microcephaly were not directly investigated.

ASPM (Bond et al., 2002) and WDR62 (Bilgüvar et al., 2010; Nicholas et al., 2010) are the two major causal genes for primary microcephaly and for which the pathological mechanisms have also recently been associated to PC anomalies. Both proteins were previously involved in centrosomerelated functions (centriole duplication) where they co-localize. Their disruption in mice leads to PC defects as well as to abnormal mother centriole/ciliary remnant asymmetric inheritance, subsequently resulting in abnormal NSPC fate determination as a result of the abnormal sensing of extracellular cues mediated by the PC (Jayaraman et al., 2016). Similarly, loss of Katnb1 in mice, a gene involved in severe cases of primary microcephaly with gyration defects in humans (Hu et al., 
2014; Mishra-Gorur et al., 2014), leads to abnormal SHH signaling, likely due to the presence of supernumerary centrioles and PC, thus suggesting possible cilia-dependent signaling defects in the mechanisms underlying microcephaly due to mutations in this gene. Finally, mutations in STIL have been reported in isolated microcephaly cases (Kumar et al., 2009) as well as in microcephaly cases with HPE (Kakar et al., 2015; Mouden et al., 2015). STIL is required for centriolar duplication and its depletion resulted in both ciliogenesis (Vulprecht et al., 2012) and PC/SHH signaling defects (David et al., 2014), suggesting once more the possible involvement of PC-dependent signaling defects in the mechanisms underlying microcephaly.

The role of ciliary defects in microcephaly was more directly investigated in the case of mutations in CPAP/CENPJ, first identified in isolated microcephaly in humans (Bond et al., 2005), but also in Seckel syndrome (MIM \#210600), belonging to the group of MPD disorders (AI-Dosari et al., 2010). CPAP has been shown to negatively regulate the length of centrioles and cilia (Kohlmaier et al., 2009; Schmidt et al., 2009; Tang et al., 2009; Wu and Tang, 2012). Disease causing mutations in CPAP/CENPJ result in longer PC in NSPC, increasing the length of time required for disassembly prior to mitosis (Figure $1 A)$. As a consequence, cell cycle $\left(G_{1} / S\right.$ transition) is delayed, leading to the premature switch of progenitors from a proliferative to a differentiating state (Gabriel et al., 2016). Similar observations were initially made for Tctex-1 (or DNYLT1), a dynein-associated protein which negatively regulates ciliary disassembly (Li et al., 2011), NDE1 (Kim et al., 2011; Doobin et al., 2016), a partner of CPAP involved in severe forms of microcephaly (Alkuraya et al., 2011; Bakircioglu et al., 2011), and more recently for KIF2A (Broix et al., 2018), a kinesin involved in ciliary disassembly upon cell-cycle reentry (Miyamoto et al., 2015) for which mutations were identified in MCD cases (Poirier et al., 2013; Cavallin et al., 2017).

Interestingly, PC in NSPC were also implicated in the signaling of Insulin-like growth factors (IGF-I and IGF-II) which are both secreted in the CSF by the choroid plexus. The IGF-I receptor (IGF1R) was localized at the ciliary membrane of NSPCS and its activation by IGF-I was implicated in cilia resorption through phosphorylation of Tctex-1, therefore allowing S-phase progression (Yeh et al., 2013). It is therefore likely that IGF1 and IGF2 control NSPC proliferation of NSPC through PCdependent IGF1R mediated signaling (Lehtinen et al., 2011), in agreement with the fact that mutations of both IGF1 (Woods et al., 1996) and IGF1R (Abuzzahab et al., 2003) or their invalidation in mice (Beck et al., 1995; Lehtinen et al., 2011) lead to microcephaly, in addition to global growth restriction.

Finally, among the "classical" ciliopathy spectrum, microcephaly is one of the features defining the OFD type XIV, a ciliopathy caused by mutations in C2CD3 (Thauvin-Robinet et al., 2014). C2CD3 is required for the elongation of the distal end of centrioles, a step essential for the docking and biogenesis of subdistal and distal appendages at the mother centriole (Thauvin-Robinet et al., 2014; 
Ye et al., 2014). Impairing the assembly of distal appendages results in strong ciliogenesis defects (Graser et al., 2007; Tanos et al., 2013), likely explaining the ciliopathy phenotypes observed upon mutations in C2CD3 (Thauvin-Robinet et al., 2014). However, the direct contribution of the observed ciliogenesis defects to the etiology of microcephaly remains to be determined in this case as C2CD3 also possesses centriolar-specific functions, including a role in the biogenesis of subdistal appendages (Thauvin-Robinet et al., 2014), upon which cytoplasmic microtubules are anchored, which could also contribute to the observed microcephaly.

All these results based on both human genetics and murine model studies, strongly suggest PC anomalies as a potential pathological mechanisms underlying primary microcephaly. Accordingly, studies on developmental cell biology have extensively stressed the role of PC in cerebral cortical development. Firstly, all NSPC have been shown to harbor a PC which is localized the apical membrane of apical progenitors and thus in a strategic location to sense and transduce signals from the CSF (Figure 4A,B). Besides its important role in SHH signaling, PC have now clearly been described as playing a key role in the control of cell cycle progression and, therefore, for the expansion/commitment of progenitor required for normal cerebral cortical size and folding (reviewed in (Youn and Han, 2018)). For instance, at the onset of cortical neurogenesis, increasing numbers of apical progenitors switch from symmetric to asymmetric divisions, resulting in the selfrenewal of apical progenitors and the generation of basal progenitors located deeper in the developing cortex. Interestingly, the delamination of basal progenitors (loss of apical membrane and retraction toward the basal side) is preceded by the assembly of a basolateral rather than apical PC (Wilsch-Brauninger et al., 2012). These basally localized cilia are thought to transduce specific signals, no longer from the CSF, but rather from neighboring cells or from molecules present in the intercellular space, potentially promoting the switch from apical to basal progenitors, including delamination. As another exciting example, during the asymmetric division of NSPC, the cilium is disassembled and the mother centriole of the older centrosome (basal body) remains associated to a ciliary membrane remnant (Figures $1 \mathrm{~A}$ and $4 \mathrm{~B}$ ) that is therefore asymmetrically transmitted to one of the two daughter cells (Anderson and Stearns, 2009; Paridaen et al., 2013). The inheritance of this pre-primed mother centriole allows the quicker assembly of a functional cilia at the apical surface which appears to dictate the progenitor state statue to the corresponding daughter cell (Paridaen et al., 2013), suggesting that the asymmetric inheritance of the centriole-ciliary membrane remnant participates to the control of NSPC fate. Finally, PC were also involved in apico-basal polarity of radial glial cells scaffold supporting neuronal migration (Higginbotham et al., 2013) or during interneurons tangential migration to the cortical plate (Baudoin et al., 2012). All of these observations are indeed clearly pointing to a key role of PC during cortical development in addition to its well accepted role during early steps of neural tube patterning and closure. 


\section{Conclusion}

Since the discovery of the link between cilia and SHH signaling in the neural tube in 2003, extensive progress has been made in the understanding of the mechanisms underlying cerebral defects in ciliopathy patients. Most of the evidence comes from studies in animal models, however, some studies conducted in human fetal tissues or cells confirmed similar underlying mechanisms. SHH signaling has been the focus of most studies whereas the involvement of other PC-dependent signaling pathways remains to be further explored. While hydrocephalus, corpus callosum malformations, cerebellar hypoplasia and NTD are classically considered as belonging to the clinical spectrum of ciliopathies, it was not the case for primary microcephaly, even in cases of mutations in genes encoding centrosome-associated proteins which were generally thought to primarily affect their functions in microtubules dynamics and/or spindle orientation/organization. However, the significance of PC function during cerebral cortical development now appears evident as PC dynamics and signaling defects have been demonstrated in the context of primary microcephaly, with or without MCD. It is also strengthened by the various neurological features exhibited almost constantly by individuals diagnosed with ciliopathies, including cognitive deficits, autism spectrum disorders and seizures, which also suggest more subtle cortical defects. Nevertheless, as pointed out in this review, it remains challenging to distinguish the relative contributions of the function of primary microcephaly gene products at the centrosome and/or PC since defects in centriolar duplication or the assembly of mother centriole appendages would have a dual impact on centriole-associated processes (spindle organization and orientation, nucleation and anchoring of microtubules) as well as on ciliogenesis. 


\section{Acknowledgements:}

The authors would like to thank Tania Attié-Bitach and Ferechté Razavi for their comments on the manuscript and their kind gift of brain pictures in Figure 3, as well as Françoise and François Broche for their warm welcome during the writing of the first version of this review (A.B.). The work in the labs of the authors were supported by the Agence Nationale de la Recherche (ANR; ANR-13-BSV10027, ANR-17-CE16-0003-01), the Fondation pour la Recherche Médicale (DEQ20130326532) and the GIS-Institut des Maladies Rares (AMA11025KSA). The Imagine Institute is supported by State funding from the ANR under "Investissements d'avenir" program (ANR-10-IAHU-01) and as part of the second "Investissements d'Avenir" program (ANR-17-RHUS-0002). LB is supported by the ANR under "Investissements d'avenir" program (ANR-10-IAHU-01) and the Fondation Bettencourt Schueller (MD-PhD program).

\section{Conflict of interest:}

None to declare. 


\section{References:}

Abuzzahab, MJ et al. (2003). IGF-I receptor mutations resulting in intrauterine and postnatal growth retardation. N Engl J Med 349, 2211-2222.

Aguilar, A, Meunier, A, Strehl, L, Martinovic, J, Bonniere, M, Attie-Bitach, T, Encha-Razavi, F, and Spassky, N (2012). Analysis of human samples reveals impaired SHH-dependent cerebellar development in Joubert syndrome/Meckel syndrome. Proc Natl Acad Sci USA 109, 16951-16956.

Al-Dosari, MS, Shaheen, R, Colak, D, and Alkuraya, FS (2010). Novel CENPJ mutation causes Seckel syndrome. J Med Genet 47, 411-414.

Alkuraya, FS et al. (2011). Human mutations in NDE1 cause extreme microcephaly with lissencephaly [corrected]. Am J Hum Genet 88, 536-547.

Anderson, CT, and Stearns, T (2009). Centriole age underlies asynchronous primary cilium growth in mammalian cells. Curr Biol 19, 1498-1502.

Andreu-Cervera, A, Anselme, I, Karam, A, Laclef, C, Catala, M, and Schneider-Maunoury, S (2019). The ciliopathy gene $\mathrm{ftm} / \mathrm{rpgrip} 1 \mathrm{l}$ controls mouse forebrain patterning via region-specific modulation of hedgehog/gli signaling. J Neurosci.

Ansley, SJ et al. (2003). Basal body dysfunction is a likely cause of pleiotropic Bardet-Biedl syndrome. Nature 425, 628-633.

Bakircioglu, $M$ et al. (2011). The essential role of centrosomal NDE1 in human cerebral cortex neurogenesis. Am J Hum Genet 88, 523-535.

Bangs, F, and Anderson, KV (2017). Primary Cilia and Mammalian Hedgehog Signaling. Cold Spring Harb Perspect Biol 9.

Banizs, B, Pike, MM, Millican, CL, Ferguson, WB, Komlosi, P, Sheetz, J, Bell, PD, Schwiebert, EM, and Yoder, BK (2005). Dysfunctional cilia lead to altered ependyma and choroid plexus function, and result in the formation of hydrocephalus. Development 132, 5329-5339.

Baudoin, J-P et al. (2012). Tangentially migrating neurons assemble a primary cilium that promotes their reorientation to the cortical plate. Neuron 76, 1108-1122.

Beck, KD, Powell-Braxton, L, Widmer, HR, Valverde, J, and Hefti, F (1995). Igf1 gene disruption results in reduced brain size, CNS hypomyelination, and loss of hippocampal granule and striatal parvalbumin-containing neurons. Neuron $14,717-730$.

Benadiba, C et al. (2012). The ciliogenic transcription factor RFX3 regulates early midline distribution of guidepost neurons required for corpus callosum development. PLoS Genet 8, e1002606.

Besse, L, Neti, M, Anselme, I, Gerhardt, C, Rüther, U, Laclef, C, and Schneider-Maunoury, S (2011). Primary cilia control telencephalic patterning and morphogenesis via Gli3 proteolytic processing. Development 138, 2079-2088.

Biesecker, LG (2008). The Greig cephalopolysyndactyly syndrome. Orphanet J Rare Dis 3, 10.

Bilgüvar, $\mathrm{K}$ et al. (2010). Whole-exome sequencing identifies recessive WDR62 mutations in severe brain malformations. Nature 467, 207-210. 
Bober, MB, and Jackson, AP (2017). Microcephalic Osteodysplastic Primordial Dwarfism, Type II: a Clinical Review. Curr Osteoporos Rep 15, 61-69.

Bond, J et al. (2002). ASPM is a major determinant of cerebral cortical size. Nat Genet 32, 316-320.

Bond, J et al. (2005). A centrosomal mechanism involving CDK5RAP2 and CENPJ controls brain size. Nat Genet 37, 353-355.

Broix, L et al. (2018). Ciliogenesis and cell cycle alterations contribute to KIF2A-related malformations of cortical development. Hum Mol Genet 27, 224-238.

Cavallin, M et al. (2017). Recurrent KIF2A mutations are responsible for classic lissencephaly. Neurogenetics $18,73-79$.

Chartier, $\mathrm{S}$ et al. (2018). A neuropathological study of novel RTTN gene mutations causing a familial microcephaly with simplified gyral pattern. Birth Defects Res 110, 598-602.

Chiang, C, Litingtung, Y, Lee, E, Young, KE, Corden, JL, Westphal, H, and Beachy, PA (1996). Cyclopia and defective axial patterning in mice lacking Sonic hedgehog gene function. Nature 383, 407-413.

Chizhikov, VV, Davenport, J, Zhang, Q, Shih, EK, Cabello, OA, Fuchs, JL, Yoder, BK, and Millen, KJ (2007). Cilia proteins control cerebellar morphogenesis by promoting expansion of the granule progenitor pool. J Neurosci 27, 9780-9789.

Cooper, AF, Yu, KP, Brueckner, M, Brailey, LL, Johnson, L, McGrath, JM, and Bale, AE (2005). Cardiac and CNS defects in a mouse with targeted disruption of suppressor of fused. Development 132, 4407-4417.

Dammermann, A, Pemble, H, Mitchell, BJ, McLeod, I, Yates, JR, Kintner, C, Desai, AB, and Oegema, K (2009). The hydrolethalus syndrome protein HYLS-1 links core centriole structure to cilia formation. Genes Dev 23, 2046-2059.

David, A et al. (2014). Lack of centrioles and primary cilia in STIL(-/-) mouse embryos. Cell Cycle 13, 2859-2868.

Delaval, B, and Doxsey, SJ (2010). Pericentrin in cellular function and disease. J Cell Biol 188, 181190.

Doobin, DJ, Dantas, TJ, and Vallee, RB (2017). Microcephaly as a cell cycle disease. Cell Cycle 16, 247248.

Doobin, DJ, Kemal, S, Dantas, TJ, and Vallee, RB (2016). Severe NDE1-mediated microcephaly results from neural progenitor cell cycle arrests at multiple specific stages. Nat Commun 7, 12551.

Dowdle, WE et al. (2011). Disruption of a ciliary B9 protein complex causes Meckel syndrome. Am J Hum Genet 89, 94-110.

Dubourg, C, Kim, A, Watrin, E, de Tayrac, M, Odent, S, David, V, and Dupé, V (2018). Recent advances in understanding inheritance of holoprosencephaly. Am J Med Genet C Semin Med Genet 178, 258269.

Edwards, TJ, Sherr, EH, Barkovich, AJ, and Richards, LJ (2014). Clinical, genetic and imaging findings identify new causes for corpus callosum development syndromes. Brain 137, 1579-1613. 
Faheem, M et al. (2015). Molecular genetics of human primary microcephaly: an overview. BMC Med Genomics 8 Suppl 1, S4.

Ferrante, MI, Zullo, A, Barra, A, Bimonte, S, Messaddeq, N, Studer, M, Dollé, P, and Franco, B (2006). Oral-facial-digital type I protein is required for primary cilia formation and left-right axis specification. Nat Genet 38, 112-117.

Gabriel, E et al. (2016). CPAP promotes timely cilium disassembly to maintain neural progenitor pool. EMBO J 35, 803-819.

Galati, DF, Sullivan, KD, Pham, AT, Espinosa, JM, and Pearson, CG (2018). Trisomy 21 Represses Cilia Formation and Function. Dev Cell 46, 641-650.e6.

Garcia-Gonzalo, FR et al. (2011). A transition zone complex regulates mammalian ciliogenesis and ciliary membrane composition. Nat Genet 43, 776-784.

Goodrich, LV, Milenković, L, Higgins, KM, and Scott, MP (1997). Altered neural cell fates and medulloblastoma in mouse patched mutants. Science 277, 1109-1113.

Graser, S, Stierhof, Y-D, Lavoie, SB, Gassner, OS, Lamla, S, Le Clech, M, and Nigg, EA (2007). Cep164, a novel centriole appendage protein required for primary cilium formation. J Cell Biol 179, 321-330.

Greene, NDE, and Copp, AJ (2014). Neural tube defects. Annu Rev Neurosci 37, 221-242.

Guemez-Gamboa, A, Coufal, NG, and Gleeson, JG (2014). Primary cilia in the developing and mature brain. Neuron 82, 511-521.

Hansen, DV, Lui, JH, Parker, PRL, and Kriegstein, AR (2010). Neurogenic radial glia in the outer subventricular zone of human neocortex. Nature 464, 554-561.

Hatten, ME, and Roussel, MF (2011). Development and Cancer of the Cerebellum. Trends Neurosci 34, 134-142.

Higginbotham, $\mathrm{H}$ et al. (2013). Arl13b-regulated cilia activities are essential for polarized radial glial scaffold formation. Nat Neurosci 16, 1000-1007.

Hossain, M, and Stillman, B (2012). Meier-Gorlin syndrome mutations disrupt an Orc1 CDK inhibitory domain and cause centrosome reduplication. Genes Dev 26, 1797-1810.

Hu, WF et al. (2014). Katanin p80 regulates human cortical development by limiting centriole and cilia number. Neuron 84, 1240-1257.

Huangfu, D, Liu, A, Rakeman, AS, Murcia, NS, Niswander, L, and Anderson, KV (2003). Hedgehog signalling in the mouse requires intraflagellar transport proteins. Nature 426, 83-87.

Jayaraman, D et al. (2016). Microcephaly Proteins Wdr62 and Aspm Define a Mother Centriole Complex Regulating Centriole Biogenesis, Apical Complex, and Cell Fate. Neuron 92, 813-828.

Joubert, M, Eisenring, JJ, Robb, JP, and Andermann, F (1969). Familial agenesis of the cerebellar vermis. A syndrome of episodic hyperpnea, abnormal eye movements, ataxia, and retardation. Neurology 19, 813-825. 
Joubert, M, Eisenring, JJ, Robb, JP, and Andermann, F (1999). Familial agenesis of the cerebellar vermis: a syndrome of episodic hyperpnea, abnormal eye movements, ataxia, and retardation. 1969. J Child Neurol 14, 554-564.

Jurczyk, A, Gromley, A, Redick, S, San Agustin, J, Witman, G, Pazour, GJ, Peters, DJM, and Doxsey, S (2004). Pericentrin forms a complex with intraflagellar transport proteins and polycystin-2 and is required for primary cilia assembly. J Cell Biol 166, 637-643.

Kakar, N, Ahmad, J, Morris-Rosendahl, DJ, Altmüller, J, Friedrich, K, Barbi, G, Nürnberg, P, Kubisch, C, Dobyns, WB, and Borck, G (2015). STIL mutation causes autosomal recessive microcephalic lobar holoprosencephaly. Hum Genet 134, 45-51.

Kheradmand Kia, $\mathrm{S}$ et al. (2012). RTTN mutations link primary cilia function to organization of the human cerebral cortex. Am J Hum Genet 91, 533-540.

Kim, A et al. (2019). Integrated clinical and omics approach to rare diseases: novel genes and oligogenic inheritance in holoprosencephaly. Brain 142, 35-49.

Kim, S, Zaghloul, NA, Bubenshchikova, E, Oh, EC, Rankin, S, Katsanis, N, Obara, T, and Tsiokas, L (2011). Nde1-mediated inhibition of ciliogenesis affects cell cycle re-entry. Nat Cell Biol 13, 351-360.

Klingseisen, A, and Jackson, AP (2011). Mechanisms and pathways of growth failure in primordial dwarfism. Genes Dev 25, 2011-2024.

Kohlmaier, G, Loncarek, J, Meng, X, McEwen, BF, Mogensen, MM, Spektor, A, Dynlacht, BD, Khodjakov, A, and Gönczy, P (2009). Overly long centrioles and defective cell division upon excess of the SAS-4-related protein CPAP. Curr Biol 19, 1012-1018.

Kumar, A, Girimaji, SC, Duvvari, MR, and Blanton, SH (2009). Mutations in STIL, encoding a pericentriolar and centrosomal protein, cause primary microcephaly. Am J Hum Genet 84, 286-290.

Laclef, C et al. (2015). The role of primary cilia in corpus callosum formation is mediated by production of the Gli3 repressor. Hum Mol Genet 24, 4997-5014.

Lancaster, MA, Schroth, J, and Gleeson, JG (2011). Subcellular spatial regulation of canonical Wnt signalling at the primary cilium. Nat Cell Biol 13, 700-707.

Lechtreck, KF (2015). IFT-Cargo Interactions and Protein Transport in Cilia. Trends Biochem Sci 40, 765-778.

Lee, L (2013). Riding the wave of ependymal cilia: genetic susceptibility to hydrocephalus in primary ciliary dyskinesia. J Neurosci Res 91, 1117-1132.

Lehtinen, MK et al. (2011). The cerebrospinal fluid provides a proliferative niche for neural progenitor cells. Neuron 69, 893-905.

Li, A, Saito, M, Chuang, J-Z, Tseng, Y-Y, Dedesma, C, Tomizawa, K, Kaitsuka, T, and Sung, C-H (2011). Ciliary transition zone activation of phosphorylated Tctex-1 controls ciliary resorption, S-phase entry and fate of neural progenitors. Nat Cell Biol 13, 402-411.

Liem, KF, He, M, Ocbina, PJR, and Anderson, KV (2009). Mouse Kif7/Costal2 is a cilia-associated protein that regulates Sonic hedgehog signaling. Proc Natl Acad Sci USA 106, 13377-13382. 
Lui, JH, Hansen, DV, and Kriegstein, AR (2011). Development and evolution of the human neocortex. Cell 146, 18-36.

Maerz, LD, Casar Tena, T, Gerhards, J, Donow, C, Jeggo, PA, and Philipp, M (2019). Analysis of cilia dysfunction phenotypes in zebrafish embryos depleted of Origin recognition complex factors. Eur J Hum Genet.

Maria, BL et al. (1997). "Joubert syndrome" revisited: key ocular motor signs with magnetic resonance imaging correlation. J Child Neurol 12, 423-430.

Martin, C-A et al. (2014). Mutations in PLK4, encoding a master regulator of centriole biogenesis, cause microcephaly, growth failure and retinopathy. Nat Genet 46, 1283-1292.

Martinez-Campos, M, Basto, R, Baker, J, Kernan, M, and Raff, JW (2004). The Drosophila pericentrinlike protein is essential for cilia/flagella function, but appears to be dispensable for mitosis. J Cell Biol $165,673-683$.

Mishra-Gorur, K et al. (2014). Mutations in KATNB1 cause complex cerebral malformations by disrupting asymmetrically dividing neural progenitors. Neuron 84, 1226-1239.

Mitchison, HM, and Valente, EM (2017). Motile and non-motile cilia in human pathology: from function to phenotypes. J Pathol 241, 294-309.

Miyamoto, T, Hosoba, K, Ochiai, H, Royba, E, Izumi, H, Sakuma, T, Yamamoto, T, Dynlacht, BD, and Matsuura, S (2015). The Microtubule-Depolymerizing Activity of a Mitotic Kinesin Protein KIF2A Drives Primary Cilia Disassembly Coupled with Cell Proliferation. Cell Rep.

Morris-Rosendahl, DJ, and Kaindl, AM (2015). What next-generation sequencing (NGS) technology has enabled us to learn about primary autosomal recessive microcephaly (MCPH). Mol Cell Probes 29, 271-281.

Mouden, C et al. (2015). Homozygous STIL mutation causes holoprosencephaly and microcephaly in two siblings. PLoS ONE 10, e0117418.

Naveed, M, Kazmi, SK, Amin, M, Asif, Z, Islam, U, Shahid, K, and Tehreem, S (2018). Comprehensive review on the molecular genetics of autosomal recessive primary microcephaly (MCPH). Genet Res (Camb) 100, e7.

Nicholas, AK et al. (2010). WDR62 is associated with the spindle pole and is mutated in human microcephaly. Nat Genet 42, 1010-1014.

Nikolopoulou, E, Galea, GL, Rolo, A, Greene, NDE, and Copp, AJ (2017). Neural tube closure: cellular, molecular and biomechanical mechanisms. Development 144, 552-566.

Nishimura, Y, Kasahara, K, Shiromizu, T, Watanabe, M, and Inagaki, M (2019). Primary Cilia as Signaling Hubs in Health and Disease. Adv Sci (Weinh) 6, 1801138.

Nonaka-Kinoshita, M, Reillo, I, Artegiani, B, Martínez-Martínez, MÁ, Nelson, M, Borrell, V, and Calegari, $F$ (2013). Regulation of cerebral cortex size and folding by expansion of basal progenitors. EMBO J 32, 1817-1828. 
Paridaen, JTML, Wilsch-Bräuninger, $M$, and Huttner, WB (2013). Asymmetric inheritance of centrosome-associated primary cilium membrane directs ciliogenesis after cell division. Cell 155, 333-344.

Passemard, S et al. (2009). Expanding the clinical and neuroradiologic phenotype of primary microcephaly due to ASPM mutations. Neurology 73, 962-969.

Persson, M, Stamataki, D, te Welscher, P, Andersson, E, Böse, J, Rüther, U, Ericson, J, and Briscoe, J (2002). Dorsal-ventral patterning of the spinal cord requires Gli3 transcriptional repressor activity. Genes Dev 16, 2865-2878.

Poirier, $\mathrm{K}$ et al. (2013). Mutations in TUBG1, DYNC1H1, KIF5C and KIF2A cause malformations of cortical development and microcephaly. Nat Genet 45, 639-647.

Putoux, A et al. (2011). KIF7 mutations cause fetal hydrolethalus and acrocallosal syndromes. Nat Genet 43, 601-606.

Putoux, A, Baas, D, Paschaki, M, Morlé, L, Maire, C, Attié-Bitach, T, Thomas, S, and Durand, B (2018). Altered GLI3 and FGF8 signaling underlies Acrocallosal syndrome phenotypes in Kif7 depleted mice. Hum Mol Genet.

Rauch, A et al. (2008). Mutations in the pericentrin (PCNT) gene cause primordial dwarfism. Science $319,816-819$.

Reilly, ML, and Benmerah, A (2019). Ciliary kinesins beyond IFT: cilium length, disassembly, cargo transport and signaling. Biol Cell.

Reiter, JF, and Leroux, MR (2017). Genes and molecular pathways underpinning ciliopathies. Nat Rev Mol Cell Biol 18, 533-547.

Ribes, V, and Briscoe, J (2009). Establishing and interpreting graded Sonic Hedgehog signaling during vertebrate neural tube patterning: the role of negative feedback. Cold Spring Harb Perspect Biol 1, a002014.

Romero, DM, Bahi-Buisson, N, and Francis, F (2018). Genetics and mechanisms leading to human cortical malformations. Semin Cell Dev Biol 76, 33-75.

Sánchez, I, and Dynlacht, BD (2016). Cilium assembly and disassembly. Nat Cell Biol 18, 711-717.

Satir, P, and Christensen, ST (2007). Overview of structure and function of mammalian cilia. Annu Rev Physiol 69, 377-400.

Schmidt, TI, Kleylein-Sohn, J, Westendorf, J, Le Clech, M, Lavoie, SB, Stierhof, Y-D, and Nigg, EA (2009). Control of centriole length by CPAP and CP110. Curr Biol 19, 1005-1011.

Shimada, IS, and Mukhopadhyay, S (2017). G-protein-coupled receptor signaling and neural tube closure defects. Birth Defects Res 109, 129-139.

Singla, V, Romaguera-Ros, M, Garcia-Verdugo, JM, and Reiter, JF (2010). Ofd1, a human disease gene, regulates the length and distal structure of centrioles. Dev Cell 18, 410-424. 
Spassky, N, Han, Y-G, Aguilar, A, Strehl, L, Besse, L, Laclef, C, Ros, MR, Garcia-Verdugo, JM, and Alvarez-Buylla, A (2008). Primary cilia are required for cerebellar development and Shh-dependent expansion of progenitor pool. Dev Biol 317, 246-259.

Spassky, N, and Meunier, A (2017). The development and functions of multiciliated epithelia. Nat Rev Mol Cell Biol 18, 423-436.

Stiff, T, Alagoz, M, Alcantara, D, Outwin, E, Brunner, HG, Bongers, EMHF, O'Driscoll, M, and Jeggo, PA (2013). Deficiency in origin licensing proteins impairs cilia formation: implications for the aetiology of Meier-Gorlin syndrome. PLoS Genet 9, e1003360.

Tang, C-JC, Fu, R-H, Wu, K-S, Hsu, W-B, and Tang, TK (2009). CPAP is a cell-cycle regulated protein that controls centriole length. Nat Cell Biol 11, 825-831.

Tanos, BE, Yang, H-J, Soni, R, Wang, W-J, Macaluso, FP, Asara, JM, and Tsou, M-FB (2013). Centriole distal appendages promote membrane docking, leading to cilia initiation. Genes Dev 27, 163-168.

Thauvin-Robinet, C et al. (2013). OFD1 mutations in males: phenotypic spectrum and ciliary basal body docking impairment. Clin Genet 84, 86-90.

Thauvin-Robinet, $C$ et al. (2014). The oral-facial-digital syndrome gene C2CD3 encodes a positive regulator of centriole elongation. Nat Genet 46, 905-911.

Theil, T, Alvarez-Bolado, G, Walter, A, and Rüther, U (1999). Gli3 is required for Emx gene expression during dorsal telencephalon development. Development 126, 3561-3571.

Thomas, S et al. (2012). TCTN3 mutations cause Mohr-Majewski syndrome. Am J Hum Genet 91, 372-378.

Valente, EM, Dallapiccola, B, and Bertini, E (2013). Joubert syndrome and related disorders. Handb Clin Neurol 113, 1879-1888.

Vortkamp, A, Gessler, M, and Grzeschik, KH (1991). GLI3 zinc-finger gene interrupted by translocations in Greig syndrome families. Nature 352, 539-540.

Vulprecht, J et al. (2012). STIL is required for centriole duplication in human cells. J Cell Sci 125, 13531362.

Wang, C, Li, J, Meng, Q, and Wang, B (2017). Three Tctn proteins are functionally conserved in the regulation of neural tube patterning and Gli3 processing but not ciliogenesis and Hedgehog signaling in the mouse. Dev Biol 430, 156-165.

Wechsler-Reya, RJ, and Scott, MP (1999). Control of neuronal precursor proliferation in the cerebellum by Sonic Hedgehog. Neuron 22, 103-114.

Wei, Q, Zhang, Y, Schouteden, C, Zhang, Y, Zhang, Q, Dong, J, Wonesch, V, Ling, K, Dammermann, A, and $\mathrm{Hu}, \mathrm{J}(2016)$. The hydrolethalus syndrome protein HYLS-1 regulates formation of the ciliary gate. Nat Commun 7, 12437.

Wheway, G, Abdelhamed, Z, Natarajan, S, Toomes, C, Inglehearn, C, and Johnson, CA (2013). Aberrant Wnt signalling and cellular over-proliferation in a novel mouse model of Meckel-Gruber syndrome. Dev Biol 377, 55-66. 
Wilsch-Brauninger, M, Peters, J, Paridaen, JTML, and Huttner, WB (2012). Basolateral rather than apical primary cilia on neuroepithelial cells committed to delamination. Development 139, 95-105.

Woods, KA, Camacho-Hübner, C, Savage, MO, and Clark, AJ (1996). Intrauterine growth retardation and postnatal growth failure associated with deletion of the insulin-like growth factor I gene. N Engl J Med 335, 1363-1367.

Wu, K-S, and Tang, TK (2012). CPAP is required for cilia formation in neuronal cells. Biol Open 1, 559565.

Ye, X, Zeng, H, Ning, G, Reiter, JF, and Liu, A (2014). C2cd3 is critical for centriolar distal appendage assembly and ciliary vesicle docking in mammals. Proc Natl Acad Sci USA 111, 2164-2169.

Yeh, C, Li, A, Chuang, J-Z, Saito, M, Cáceres, A, and Sung, C-H (2013). IGF-1 activates a cilium-localized noncanonical GBy signaling pathway that regulates cell-cycle progression. Dev Cell 26, 358-368.

Youn, YH, and Han, Y-G (2018). Primary Cilia in Brain Development and Diseases. Am J Pathol 188, $11-22$.

Yu, K, McGlynn, S, and Matise, MP (2013). Floor plate-derived sonic hedgehog regulates glial and ependymal cell fates in the developing spinal cord. Development 140, 1594-1604.

Zhang, XM, Ramalho-Santos, M, and McMahon, AP (2001). Smoothened mutants reveal redundant roles for Shh and Ihh signaling including regulation of L/R symmetry by the mouse node. Cell 106, 781-792. 

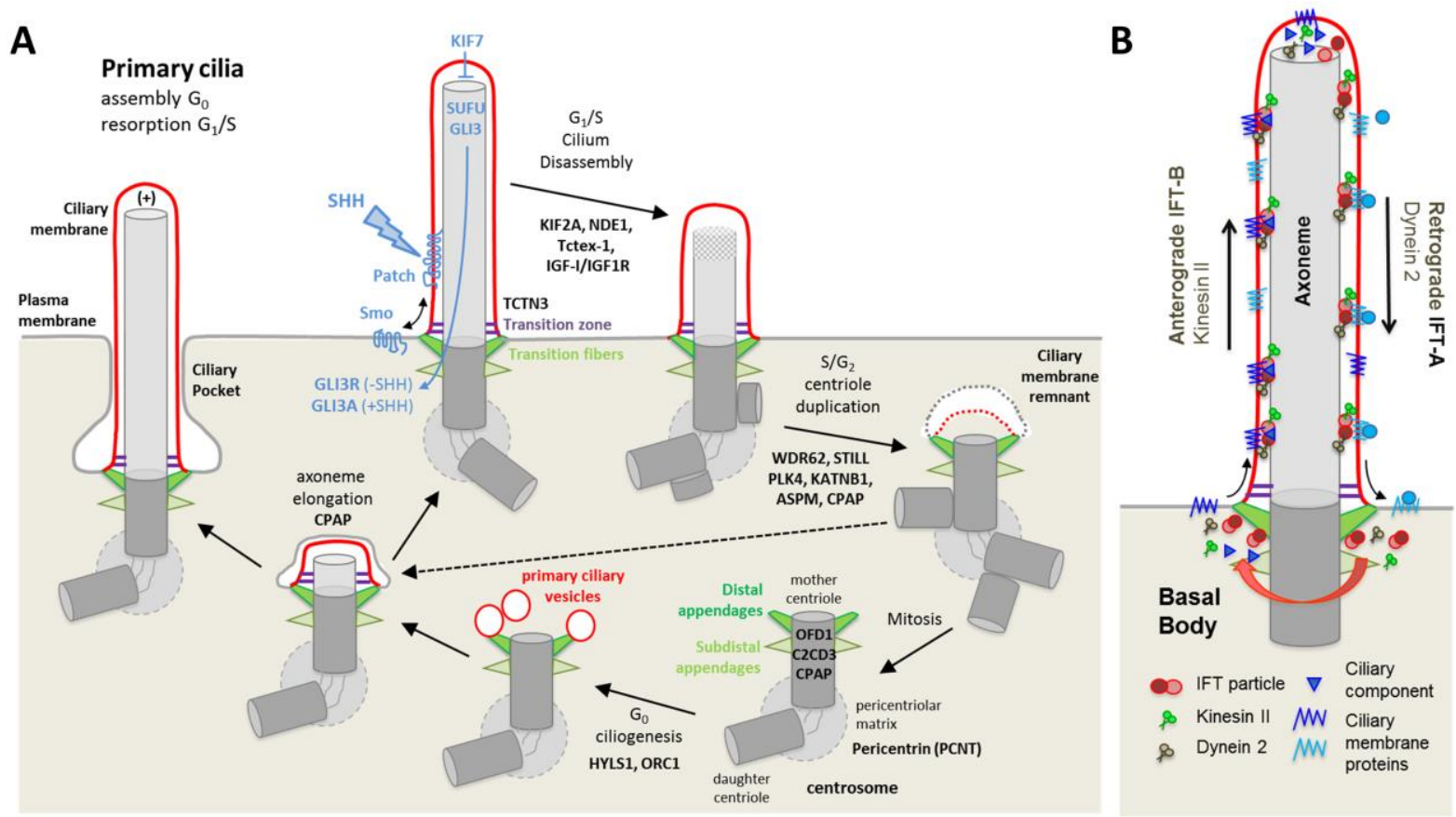

Figure 1: Assembly and disassembly of primary cilia (PC)

A. Primary cilia are formed through the elongation of the mother centriole. During ciliogenesis in quiescent cells, primary ciliary vesicles dock at the distal appendages of the mother centriole of the centrosome, incoming vesicles fuse and the axoneme elongates intracellularly before to be exported to the plasma membrane. During cell cycle reentry, the axoneme is disassembled while centrioles start to duplicate. The duplicated centrosomes then separate from the apical membrane. In the case of asymmetric divisions, a ciliary membrane remnant (CR) remains attached to the old mother centrioles only thus generating an asymmetry between daughter cells. The cell which inherits the mother centriole associated to the CR is able to reestablish a PC earlier than the other daughter cell, which has to undergo de novo early steps of ciliogenesis. B. Assembly and disassembly of PC involves the transport of proteins from the cytoplasm to the PC which is called intraflagellar transport (IFT). IFT is a bidirectional transport based on the loading of selected cargos in the cytoplasm and ciliary compartment to IFT particles powered by anterograde (Kinesin-II) and retrograde (Dynein 2) motors, allowing their transport along axonemal microtubules in and out from PC. 


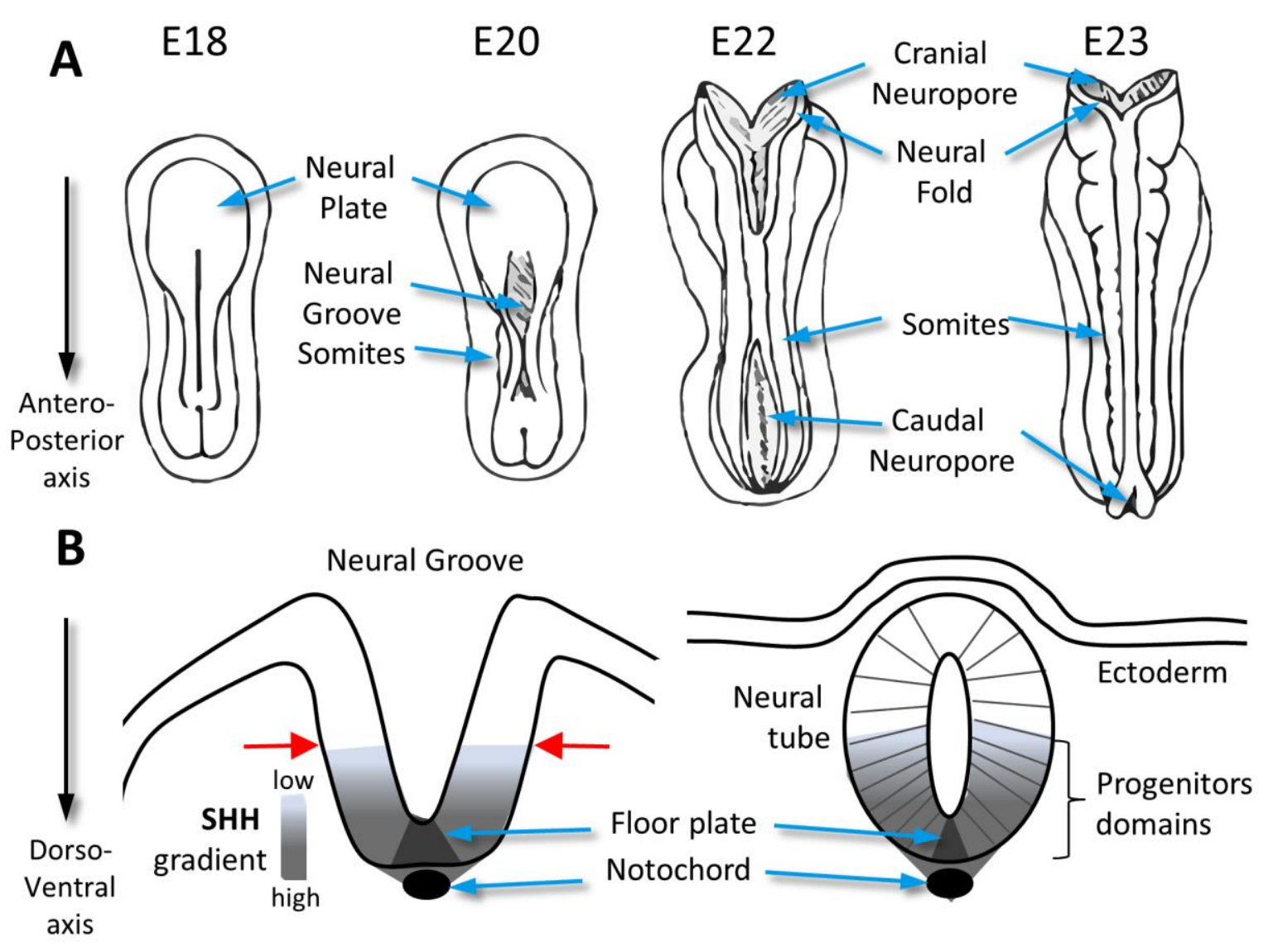

Figure 2: Neural tube closure and patterning.

A. Dorsal views of forming neural tube in the developing embryo. Day of development indicated above each scheme. B. The folding of the neural plate is induced by SHH which is secreted from the Notochord, and then by the floor plate, and forms a ventro-dorsal gradient. This SHH gradient dictates the localization of the bending events of the neural tube at the ventral midline (red arrows) where $\mathrm{SHH}$ is low. After neural tube closure, this $\mathrm{SHH}$ gradient generates various domains of progenitor cells which are arranged along the dorsal-ventral axis. 

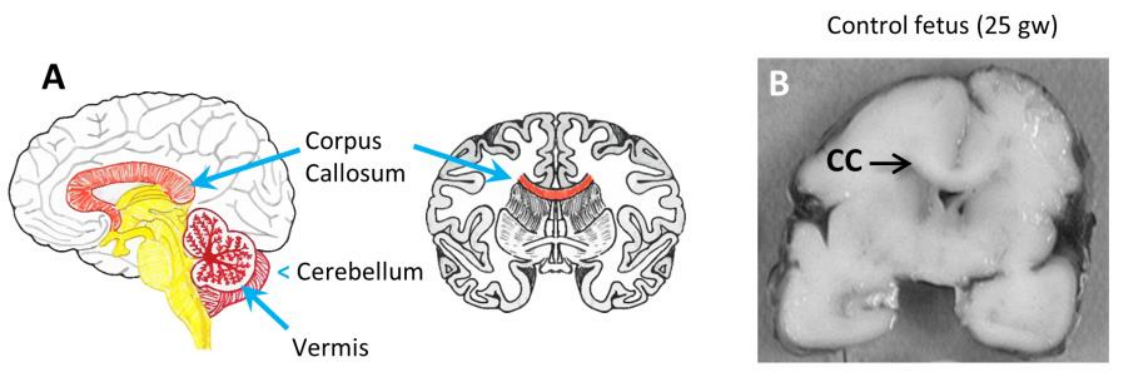

KIF7 mutated fetus (27 gw)
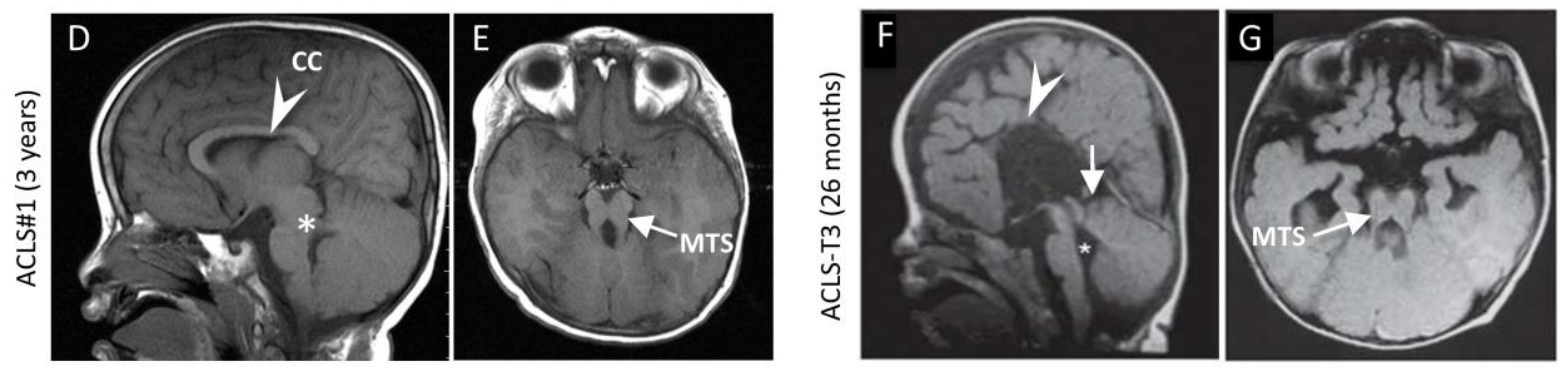

Figure 3: Brain anomalies in KIF7 mutated patients.

A. Brain organization with corpus callosum and cerebellum highlighted. B,C. Coronal slice through fixed fetal brain of control (B) and KIF7 mutated fetus (C) shows the normal appearance of corpus callosum in (B) which is absent in the mutated case with characteristic Probst bundles composed of the callosal axons that failed to cross the midline (C). D, E. Brain MRI of ACLS case 1 at 3 years from Putoux et al., 2012. D. Sagittal T1 view shows normal corpus callosum (arrowhead), and thickened superior cerebellar peduncles (white asterisk). E. Axial T1 view shows dysmorphism of the fourth ventricle with thickened and elongated superior cerebellar peduncles resulting in a molar tooth sign (arrow). F, G. Brain MRI sections in individual ACLS-T3 from Putoux et al., 2011. (F) Sagittal brain MRI showing the corpus callosum agenesis (arowhead), dysplastic superior vermis (arrows) or dilated lateral and fourth ventricle (asterisks). G. Axial view of brainstem abnormalities with deep interpeduncular fossa and stretched cerebellar peduncles. Panels B-G were used with permission from Tania Attié-Bitach and Ferechte Razavi. 
A

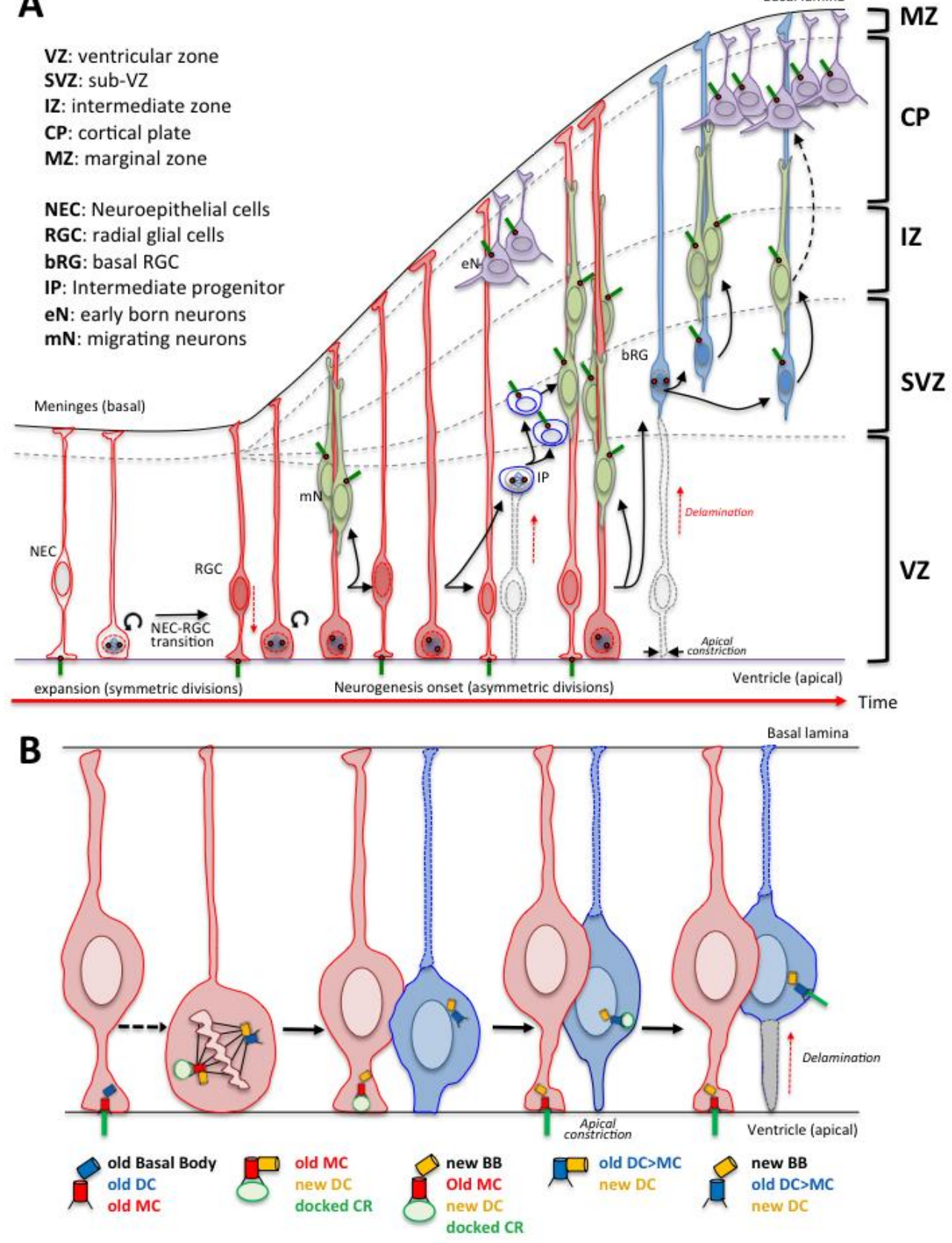

Figure 4: The developing cerebral cortex and primary cilia dynamics and location.

A. NSPC subtypes, their mode of division and their progeny are schematized. Primary cilia are present on all NSPC subtypes as well as on neurons; being apically localized on apical progenitors. B. Apical progenitors harbor a cilium (green) which is assembled from the mother centriole (basal body, red) at the apical membrane and then protrudes into the brain ventricle to sense and transduce signals from the CSF. During asymmetric division, the mother centriole retains a ciliary membrane remnant (CR, green vesicle) throughout mitosis. This CR-primed mother centriole is inherited by a daughter cell which rapidly assembles an apical PC and remains a progenitor. The second daughter cell inherits a mother centriole (blue) which was the daughter centriole in the mother cell. This new mother centriole is not pre-associated with a ciliary vesicle and therefore ciliogenesis is delayed. In addition, the newly formed cilium in this cell is not apical but basolateral, thus sensing different signals than from the CSF inducing apical constriction and delamination to finally give rise to basal progenitors (IP or bRG) or directly to neurons. 